\title{
Whose fault is failure? Contested perspectives of academic support in tertiary educational institutions in South Africa.
}

Word count (main text): 8903

Key words: Student support; Student perspectives; Academic support; Help-seeking; TVET; Vocational Education; Ethnography; Widening Participation; South Africa

\section{Abstract}

This paper explores the argument that to widen participation in higher education, educational institutions should bear a greater responsibility for students learning. Central to this debate is the notion of 'academic support'. There are many perspectives of what works to scaffold student participation and learning but rarely are the perspectives of those receiving support taken into account. This paper reports the findings of an exploratory ethnographic study in which students in a vocational college in South Africa reflected on the nature of academic support and access to it. Student narratives that underpin their understandings of how the support system 'worked', and what responsibilities they and the college respectively bore for their studies, are compared to the official prescript on student support services in South Africa - the so-called 'Student Support Services Manual' which was developed by the South African Department of Higher Education and Training (DHET).

The data indicate sharp incongruences in thinking. While the student support services manual maintains that students are a product of their disadvantaged contexts and therefore require an institutional form of academic support, students themselves placed much less responsibility for the provision of academic support on the colleges. Instead, they attributed their success or failure to 'character' and their own dispositions towards learning. This is an unexpected finding in the context of an often highly charged debate on the factors that constrain learning and learning outcomes. This paper argues that it is this 'locus of control' that undermines the idea that student success is dependent on prescription alone.

\section{Introduction}

As the international focus turns from 'access' to 'attainment' (i.e. more years spent in education) and 'achievement' (i.e. better and more relevant learning outcomes), this paper looks at where the responsibility for learning lies (World Bank, 2018). The question of 
attainment and achievement is particularly pertinent in the Technical and Vocational Education and Training (TVET) sector for two reasons. First, while countries like Brazil, Indonesia, China, and South Africa seek to improve productivity through widening access to TVET, their efforts are undermined by low through-put and graduation rates (Yi et al., 2015). Second, as this paper will argue, the question of achievement, particularly responsibility for learning, is especially acute in post-school institutions, as many learners grapple with transitions from adolescence to adulthood (Brion-Meisels, Fei, and Vasudevan, 2017). It is in this context that how to best support student learning has taken centre stage (World Bank, 2018).

The conventional approach to student attainment in higher education, especially in the United Kingdom (Gibbs 2013; Clegg, 2009), Australia and New Zealand (Manathunga 2011, 2013), and South Africa (Boughey and Niven, 2012 ), is that institutions of higher education are responsible for ensuring that their students succeed (for recent reviews, see Younger, Gascoine, Menzies and Torgerson, 2018; Webb et al., 2017). This is a relatively recent shift, and one that has been accompanied by increasingly individualised and pastoral modes of student support (Brion-Meisels et al., 2017). However, it has not been without controversy, as scholars such as Eccelstone (2004) have criticised what is described as a 'therapeutic culture', which disempowers students by reducing their agency and foregrounding their deficit.

Although educational institutions and policymakers are increasingly prioritising student support, and although there is dispute as to how that support effects students' agency, there is relatively little understanding on how students actually experience support (Powell, 2013: 75). This is particularly true in vocational education, and especially so in developing countries (Powell, 2013: 75). Drawing on the findings from an exploratory ethnographic study in which students in a vocational college in South Africa reflect on the nature of academic support and their access to it, this paper addresses this anomaly.

\section{Background}

The need for skills development, particularly for youth, is especially acute in South Africa. Approximately 3.4 million young people in South Africa between the ages of 15 and 24 are not participating in training, education or employment (NEET) (DHET, 2014: xvi). Almost all 
of NEET youth (97\%) lack a qualification from either a TVET college or a university, and the substantial majority (71\%) have not completed the final school-leaving certification (Sheppard and Cloete, 2009). Moreover, $60 \%$ of NEET youth have never been employed, and thus have no work experience (Sheppard and Cloete, 2009). These youth thus lack the requisite skills to enter the labour market, particularly one as challenging as South Africa (Mlatsheni and Ranchhod, 2017).

It is in this context that the South African government has sought to expand access to TVET. The TVET sector has a long history in South Africa. In the early $20^{\text {th }}$ century it was used originally as a means to educate students who had dropped out of the mainstream school system (Van der Bijl and Lawrence, 2018: 1). The view of the TVET as a second-class education hardened during South Africa's apartheid years (Johnson, 2008; Oketch, 2014). After 1994, the post-apartheid government attempted to increase the status of vocational education, in part through the creation of the National Qualifications Framework (NQF). The NQF brought into a single educational framework a number of "pathways of learning... from the lowest levels to the PhD, across the academic, occupational and vocational divides" (Wedekind, 2010: 304). Instead of vocational education being a second-class alternative to academia, the NQF sought to conceptualise vocational institutions as intertwined with institutions of higher education.

However, within this framework there was persistent confusion as to whether students studying towards vocational qualifications were effectively 'non-academic' school children, or aspirant technicians and craftspeople (Wedekind, 2010). Wedekind (2010: 312) has described lecturers interpreting these reforms as lowering their professional status, lamenting that they "were now high schools, not colleges". This is, at least in part, because they believed the student body to be younger than less motivated than before (Wedekind, 2010: 312). In sum, despite efforts to increase the status of vocational education, the sector remains mired with stigma that vocational learners are less mature than their academic counterparts.

Nonetheless, South Africa has made considerable progress in increasing enrolments in TVET, growing from approximately 300000 students in 2009 to 737880 students in 2012 (DHET, 2012; DHET, 2015; Sheppard \& Sheppard, 2012: 67). However, only a minority of students successfully graduate: 33\% for National Certificate (Vocational) programmes in 2013 
(Nzimande, 2014: 4). This is still a fraction of what will be required if the TVET sector is to be an adequate response to the vast numbers of youth who are currently NEET.

In response to the growing number of students with relatively low levels of formal education entering the college system, which has been seen to be a major contributory factor to low competition rates, the Department of Higher Education and Training (DHET) has identified student support services as a priority (DHET, 2014). At the time of writing, student support services are the responsibility of each college, which are required to formulate and submit proposals for funding to DHET. As this is a relatively new priority for the sector, the vast majority of colleges are currently implementing only very minimal services, if any.

The Student Support Services (SSS) Manual, which was released in 2009, is the core document that colleges use in designing their student support services. It is an instructional and supportive guide for colleges, with the purpose of helping them to assess and improve their student support services. The manual included advice on "pre-entry and entry support, on-course academic and personal support, and exit support" (Department of Education (DoE)', 2009). It foregrounds academic support as a priority, and chiefly provides guidance for improving pedagogy and administration.

Surprisingly, an explicit definition of 'student support' is absent from the SSS Manual, and it is difficult to find a definitive explanation in the surrounding literature. The academic interest in student support falls within the field of 'academic' or 'educational development'. Manathunga (2011: 347) notes that this emerged as a distinct field in the 1960s and 1970s linked to the massification of higher education and in response to concerns about rising student attrition and failure rates. Boughey and Niven (2012: 645), writing in the South African context, note the centrality of the concern and responsibility for student learning, specifically for students from poor socio-economic backgrounds. For the purposes of this paper, 'student support' may be inductively defined as intentional efforts to surmount the challenges that students encounter, which may otherwise lead to their failure or attrition. In order to analyse how students and educational authorities in South Africa conceptualise student academic support, it is helpful to consider a typography of different models of support. 


\section{The theoretical underpinnings of academic support models}

Four different models of provision of support can identified in the international literature, each with different underlying beliefs about the nature of the educational institution in question. While these models predominately refer to the perspectives of educational institutions, they are equally useful as a framework for reflecting on the perspectives of students. The four models are typified as offering students minimal or no support (i.e. "thin"); targeted support for a minority of students (i.e. "targeted"); mainstream support for the majority (i.e. "totalist"); or an overhaul of the values and competencies prioritised by the institution (i.e. "transformative").

In the "thin" model, students are conceptualised as studying independently; as being capable of, and responsible for, asking for help when it is needed (Boughey \& Niven, 2012: 467; Gibbs, 2013: 9; Manathunga, 2011). The educational institution, conversely, is understood as providing instruction, and either minimal or no further support. If students are unable to succeed under conditions of very limited support, this model argues, then the educational institution should not have admitted them (Johnson, 1995: 39).

Johnson (1995) suggests that this model is exemplified in a position taken by Afrikaans medium universities in South Africa in the early 1990s. Although these universities had lifted racial barriers to entry, equality of access was understood as selecting students according to unchanged selection criteria (Johnson, 1995: 39). These universities recognised that inequities in the schooling system would entail that very few black students would be likely to be admitted and succeed without additional support, however they argued that "universities are not the best place for addressing the inequalities and inequities of the education system" (Johnson, 1995: 39).

The "targeted" model entails targeted support for a minority of students. This maintains that the university bears at least some responsibility for addressing student disadvantage through providing support within the institution (Johnson, 1995: 39). The struggling student is considered unprepared for study at the institution and lacking in the requisite levels of competency in the language of instruction, literacy, or conceptual ability (Boughey \& Niven, 
2012: 467). In framing the 'problem' as being one of students struggling to succeed within these institutions as a result of their background, students' deficit is foregrounded (Manathunga, 2011: 355). Support is considered to be an appendage to 'real' education.

Boughey and Niven (2012: 467) describe this model as characteristic of the support provided by a number of 'white', English-medium universities in South Africa in the early 1980s. These universities had taken advantage of certain provisions in Apartheid legislation to admit a small number of black students into universities designated as exclusively for white people. Student support was thus designed as a remedial measure, auxiliary to mainstream instruction, in order to aid black students who were studying in a language different from their home language, and who were often socio-economically disadvantaged (Boughey \& Niven, 2012: 467). While many researchers critically framed these challenges as emanating from the discriminatory policies of the Apartheid state, the structures, norms and practices of the university remained unproblematised (Boughey \& Niven, 2012: 467). Manathunga (2011: 355), similarly, articulates this model of support in her analysis of the discourse of student support in higher education in Australia and New Zealand in 1970.

The "totalist" model entails changing mainstream teaching practices in the institution in order to accommodate the 'deficiencies' of a significant proportion of students. Boughey and Niven (2012: 649), Manathunga (2011) and Clegg (2009: 59) describe this as the contemporary discourse of student support in South Africa, Australia and Aotearoa New Zealand, and the UK respectively, as participation in tertiary education has widened. The provision of academic support thus may no longer be solely the responsibility of specialised support staff, but rather as techniques that must be integrated into mainstream teaching (Johnson, 1995: 40).

This model, like the previous two, foregrounds student deficit, but due to the scale of the problem locates the responsibility on the educational institution to change its teaching practices. Fundamentally, this is a shift in the notion of the nature of tertiary education; it is no longer understood as reserved for the elite, but rather as catering to the population more broadly (Boughey \& Niven, 2012: 649; Clegg, 2009: 59). Implicitly, this entails the admittance and accommodation of a larger proportion of weaker students (Boughey \& 
Niven, 2012: 649; Clegg, 2009: 59). Boughey and Niven (2012: 650) argue that this shift is underpinned by an international movement towards a discourse of skills development for economic growth, efficiency, and institutional accountability. In a discourse analysis of the educational development field in Australia and Aotearoa New Zealand, Manathunga (2013: 76) argues that a discourse of 'efficiency' and a concern for 'wastage' has permeated throughout. She demonstrates a discursive shift from locating responsibility of learning solely on the students, to the academic staff (Manathunga, 2013: 77). The 'problem' is that low graduation and throughput rates represent inefficient expenditure, and it is the educational institution's responsibility to address this in order to provide adequate support for the economy (Boughey \& Niven, 2012: 649; Clegg, 2009: 59; Manathunga, 2011). This position may be broadly identified as shaped by a neoliberal discourse.

The "transformative" model entails changing mainstream pedagogy in the institution in order to accommodate the knowledge and competencies that the students bring to the classroom. Boughey and Niven (2012: 648) argue that this was characteristic of the academic development literature in South Africa of the late 1980s and during the initial years of the new dispensation. It was borne from the realisation that in the near future black students would no longer constitute a small minority within the university. In contrast to merely providing remedial courses as had been the strategy previously, the focus for change was to adapt the pedagogical approach to use students' knowledge and language as a means of accessing the existing curricula. This was spearheaded by 'Academic Development Centres', which were established to drive change within the institution (Boughey, 2007: 28).

This model, unlike the previous three, foregrounds the socio-political nature of the educational institution and broader context, rather than the deficit of the student as an ahistorical individual. It posits that students exist within a socio-cultural context with norms and expectations that disadvantage them in a traditional university context, and which the educational institution may be responsible for maintaining (Boughey \& Niven, 2012: 648). The 'problem' is thus not that students lack objectively desirable skills and competencies, but rather that their existing competencies and ways of being are undervalued by the sociocultural context and institution in question, which consequently must change (Boughey \& 
Niven, 2012: 648). In the late 1980s, this was buttressed by a theoretical shift towards a more socio-cultural understanding of students' challenges, particularly pertaining to literacy and language, as well as increasing reference to theorists focusing on power. The challenge was reframed as being one of "social and cultural capital" within the university, as well as "hegemonic social constructs that had privileged some at the expense of others" (Boughey \& Niven, 2012: 648; Walker \& Badsha, 1993). Consequently, change must be promoted in both the structure and daily practice of the institution, and perhaps even in society more broadly (Boughey, 2007: 28). However, the extent to which this model asks for the epistemological basis of the curricula to change is unclear, and this is a continuing point of contestation in the latest decolonial movements within South African universities.

The transformative model is underpinned by markedly different assumptions to those of the totalist model. While the totalist model regards the student as lacking in the essential skills required for study, the transformative model positions the student as having social and cultural capital that is undervalued by the institution and socio-cultural context; it is the responsibility of the institution to function in a way that addresses the realities of the student, rather than the student to meet the needs of the institution. Consequently, although both models are concerned with change within the institution in response to widening participation, the nature and reason for this change differs. For the transformative model, it is an issue of social justice as students are wronged by the social constructs that privilege others at their expense. For the totalist model, it is an issue of human capital and efficiency, as the institution is responsible for producing the graduates needed by the economy.

Clegg (2009) notes the contrast between these models in the literature in South Africa, and that of the 'global north'. While both are concerned with widening participation and the massification of higher education, Clegg (2009: 59) argues that in the literature from the 'global north' this is largely framed as a pedagogical challenge "rather than a question of power or transformation". In contrast, Clegg (2009: 60) argues that as a consequence the relationship between widening participation in higher education and post-Apartheid transformation, issues of equity are foregrounded in the South African literature. Similarly, there is a greater political imperative to critique and explicitly depart from the practices of 
the past (Clegg, 2009: 60). The contemporary literature in South Africa however, may be more contested than Clegg (2009) suggests. While Boughey and Niven (2012: 650) recognise that earlier literature foregrounded concerns of equity and social justice, she maintains that the contemporary discourse within higher education in South Africa has since shifted to prioritising quality and efficiency in line with the 'global north'.

The staged nature of the four models of student support is represented in Figure 1. The 'thin' model reflects low investment of resources from the institution in respect of students' need for support. In this model few students are expected to seek support, and instead the responsibility for their academic success rests almost solely on them. The 'targeted' model reflects marginally more institutional investment, as well as a better accommodation of student needs. Although students are largely responsible for their academic achievement, the institution nonetheless bears some responsibility too. The 'totalist' model reflects high institutional investment in thinking, planning and resource allocation. The majority of students are expected to seek support and their needs are accommodated, and consequently responsibility is further concentrated in institutional arrangements. Finally, in the 'transformational' model, students' needs define the nature of academic provision. Institutional investments are high and the responsibility for student support is an integral function of institution. 


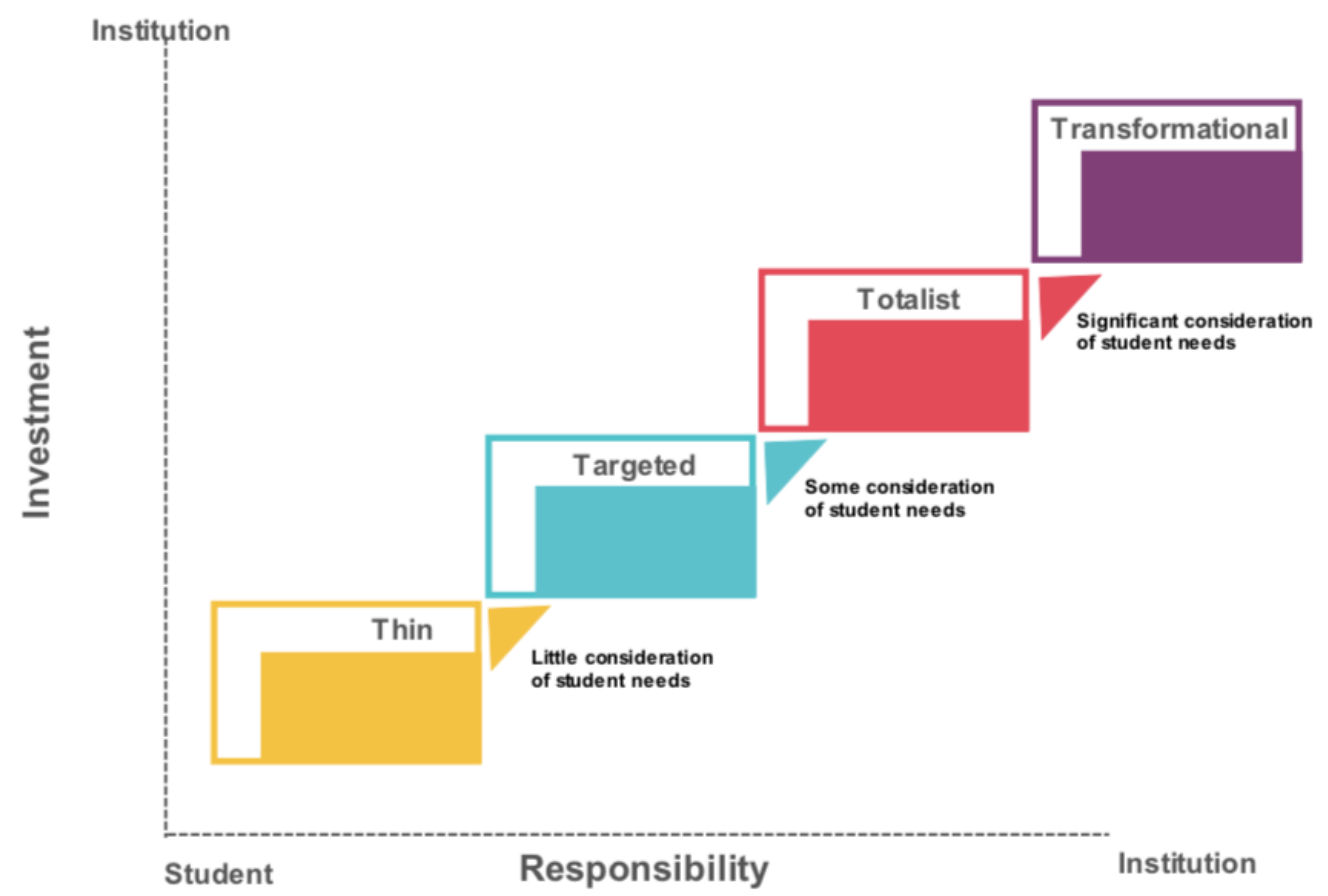

Figure 1: Framework of student support models

But what do students in South Africa think of the nature and value of the student support services offered to them by their institutions, and where do they think the 'locus of control' lies? Building on the conceptual framework offered in the figure above, this exploratory sought to gain an understanding students' perspectives of academic support, alongside the assumptions of student support as envisioned by the state.

\section{Methodology}

The study sought to understand which of the four models defined previously describes the provision of support services in TVET colleges in South Africa, and to gain deeper insight into students' perceptions of the support services offered. The exploratory nature of these research questions invited the researchers to prioritise depth and insight over statistical generalisability. The purpose of the study was to understand how students thought about their support, such as what they recognised as constituting support, and how they related to such support, and what assumptions underpinned this relationship. Consequently, an ethnographic approach was employed as being particular suitable to uncovering the lived 
experiences' and 'implicit understanding' of participants (Emerson, Fretz, and Sha, 2001: 353). The aim was to draw a diverse and varied sample from those willing to participate (Punch \& Oancea, 2009: 162). The sampling strategy was therefore purposive and selfselecting (Punch, 2014: 160).

A single TVET college, with three campuses across the city, was chosen as the empirical site of the study. This permitted greater depth and sensitivity to context than if multiple sites had been studied (Donmoyer, 2000). The site was selected because the majority of students were mother tongue speakers of the isiXhosa language, in which one of the researchers is competent. One of the researchers lived in the student hostel for the duration of the study, in order to spend time with students informally, attend classes, and interview staff members in the college. This approach recognises the importance of understanding the context in which data is collected and interpreted (Denzin, 2001: 85; Kvale, 2007: 51; Brockington and Sullivan, 2003: 57).

Of a total of 15 students that were interviewed, 7 participants approached the researchers to opt into the study after hearing about it from their peers. The researchers were also keen to interview those students identified as participating only minimally in academic life. A number of students from this category were identified and 4 were selected to participate in the study. This served as a useful counter-balance to a representation of the views of only those students with confidence to initiate contact with the researcher. However, the snowballing nature of the sample proved to yield mostly male students. The researchers sought to redress this with a purposeful selection of women students. Subsequently, 4 female students who were willing to participate in the study were interviewed after being identified by the principal of one of the campuses.

Of the 15 participants, 8 were male and 7 were female. The average length of the primary 15 interviews was approximately 50 minutes, ranging between 40 and 70 minutes. In addition, follow-up interviews were conducted with 3 participants, which typically varied between 20 and 30 minutes. 
The interview schedule investigated students' experiences entering college and asked them to identify and discuss the sources of academic support they had experienced. Following the lead of Clegg et al. (2006: 105) from their study on student help-seeking, these questions were purposefully left open so as to enable students to offer their own accounts of what constituted support. 'Academic support' was defined very broadly as what the students perceived as helping them in their studies; it was not necessarily only formal 'academic support programmes', but also asking question in class, or to their peers. The interview questions did not ask students how they related to the support formally offered by the college; rather, the interviews questions were developed in order to invite students to reflect on recent experiences in which they did not understand course material, what they did about it, and why. This enabled the researchers to investigate what sources of support students actually used, rather than asking their perspectives on specific mechanisms of support that were available.

The interview schedule was developed in two iterations. In the original version, the schedule was divided into three sections. The first section investigated how the student came to be at the college, what course they were undertaking, and how they were experiencing it. These questions were asked to build rapport with the participant, as well as contextualise their answers. The second section consisted of two broad questions, 'when are you struggling to understand something in class, what do you do?' and 'when you are struggling to understand something after class, what do you do?', with follow-up questions focusing on the details of recent occasions in which students encountered not understanding the course material. The purpose of these questions was to understand how students responded to the need for help, rather than assuming whether and how they would seek support, and asking the questions in this manner enabled students to identify sources of support that were not otherwise considered by the researchers. The final section explored other sources of support, and with the over-arching question 'if a student has any other kind of problem in college, what do they do?'. This was proceeded by three follow-up questions: 'for what kind of problems would they do that?', 'why do they do that?', and 'how do they know they can do that?'. The purpose of this section was three-fold: first, to identify other sources of support that the student does not use but is nonetheless aware of; second, to investigate 
students' understanding of how these services work; and third, to probe students' normative assumptions about under what conditions 'one' seeks support.

The interview schedule was revised after the first 3 interviews with students. In particular, students were identified as being more responsive when answering questions about specific details (such as how a particular class was, and what happened in it) rather than more general questions about the college; a tendency that is consistent with Powell's (2014:115) experience of interviewing students in TVET colleges elsewhere in South Africa. This adaptation is consistent with the iterative approach characteristic of exploratory studies, in which there is often limited information on which to base the initial research methods and questions, entailing that iteration is essential as new data is encountered (Janesick, 2000). Specifically, the second section of the schedule was revised to explore students' experiences in their first six months of college (and what information they were provided with about student support), their experiences in various classes (and whether students asked questions; and if so, how what proportion of students, and if not, what they otherwise did if they did not understand; and how this varied between different classes and why), and how students sought academic help after class and why (and how they knew how to do so).

The transcriptions and notes from the student interviews were analysed using the Listening Guide method, which entails reading the same text several times and listening for a different 'voice' each time (Brown et al., 1988; Gilligan, Spencer, Weinberg, \& Bertsch, 2006). This is a productive means of reading interviews that were otherwise too complex to adequately capture in single or unfocused readings.

The first reading of each interview considered the text holistically, and investigated what narrative the students' were constructing, and how both the researcher and the participant were positioning ourselves towards each other; "attending to what is happening and what stories are being told" (Gilligan et al., 2006: 297). The second reading focused on how the participant spoke about the college and the lecturers. The third reading focused on how the participant spoke about other students, or the student body in general. In the second and third readings, the researchers were particularly interested in the use of adjectives and in the participant's 'thick description' of these actors' behaviour; what did the student interpret was 
going on, and what motivation was being ascribed? The fourth and final reading focused on how the participant discussed using academic support.

Although this proved to be very useful in identifying commonalities and contrasts between the participants, the researchers were concerned that the broader view of the data that this afforded may comprise a detailed understanding of participants' reasoning. Each interview was consequently re-read, and four participants were selected who demonstrated the most deliberation about accessing academic support. These interviews were then each studied carefully, with a focus on how the participants built their arguments; what premises they were offering, and how they inferred conclusions from these.

Finally, on the basis of the notes from the Listening Guide and the detailed analyses, three key themes were identified which seemed salient in understanding students' deliberation. The data in the original transcripts were then categorised on the basis of these three themes.

The SSS Manual (described above) was analysed using the typography of four models, and a senior official from the DHET was interviewed in order to gain a better understanding of the intentions and interpretations underpinning the manual.

\section{Findings}

1. What model of provision best describes the student support services offered?

The SSS Manual, which was released in 2009, is the core document that colleges use in designing their student support services. It is an instructional and supportive guide for colleges, with the purpose of helping them to assess and improve their student support services.

The manual unequivocally regards student support services as needing to be "integrated" into the mainstream of the college, and thus is core to the colleges' main functions (DoE, 2009: 3). The manual argues that

"[a]Il students need academic support and development. This does not mean that each student must get special attention over and above what lecturers are able to provide in their daily teaching... [i]t means that we need to adopt a broad approach to academic support and think of it as part of the curriculum, or as part of what happens in classrooms and workshops every day" (DoE, 2009: 65) 
The SSS manual emphasises a focus on improving existing practice, rather than the provision of additional, auxiliary academic support. It puts considerable responsibility on TVET colleges to change their mainstream practices as a means of better supporting students. The 'challenge' is understood firstly as relating to a dramatic increase in enrolment, as both the manual's foreword and introduction note (DoE, 2009: 3, 5). Secondly, it is understood as resulting in a "shift in student population", which refers to challenges in regard to multiple languages, different age groups and different student needs (DoE, 2009: 5). In brief, this is representative of the 'totalist' model of student support described earlier.

\section{Students' Understandings of Academic Support}

The students in the study, on the other hand, appeared to endorse the 'thin' model of academic support, in which zero or minimal support was expected. Moreover, the students' comments about their own circumstances and those of their peers indicate that the vast majority of students accessing TVET colleges are ill-equipped to perform academically. This would suggest that the assessment made by the 'totalist' model of academic support, in which the impetus is on the institution to change in light of the pedagogical needs of the student body, is nonetheless accurate in recognising the challenges faced by the majority of students.

The students identified the primary source of academic support in the college as being the lecturers, who answered questions in class and provided additional help after class at their own discretion. Students are attuned to lecturers' behaviour and character, which they read carefully for indicators of how that lecturer may respond to requests for help. Students were also very conscious of their social standing, and how asking for help may be interpreted by their peers and lecturers.

The study outlined three themes that were relevant to how students positioned themselves towards academic support within the college. The first is that the students closely linked their responsibilities as college students to their responsibilities as adults, and conceptualised "adulthood" as entailing independence and thus independent study. Subsequently, the second theme is that of responsibility resting exclusively on one's own shoulders. Finally, the third theme is that of students not wanting to appear stupid or to be a burden. While the first two themes refer to the student not making claims on the college, 
the third theme draws on this to infer a negative assessment of oneself for requiring support at all.

\section{College and adulthood}

Students believe that being at college, and being an adult, is about independent study. This was specifically considered in contrast to school, in which teachers held greater responsibility for students' success. Eight participants framed this responsibility with reference to adulthood and maturity. For example, one student argued that students are responsible for taking their studies seriously, and lecturers cannot chase after them, because they are now 'grown-ups'. Similarly, for another:

"Here at college you have more freedom, it terms of now you are an adult, you are making decisions for yourself, no one is pushing you. In school or high school, you have your teachers who are pushing you to do your work and assignment, like some of them are after here. Whereas here, if you don't put your assignment [sic], you get a zero."

Students consequently regarded lecturers' availability after class as entirely discretionary and did not feel entitled to support outside of class. Student participants described the provision of academic support as entirely at the convenience of the lecturer. For instance, one student reported that while some lecturers are able to help students after class, one has to find fifteen minutes when they are free and are not tired. The students who were able to access support outside of class did so through arriving unannounced at the class when the lecturer had a free period, in the hope that the lecturer would be there and available, or by asking the lecturer questions through WhatsApp. Not a single student participant felt wronged by the lecturers if they were unable to see them, even if they felt as if they were never available. For instance, two students argued that lecturers were unable to help you after class because they are "always busy". Nonetheless, one prefaced this by describing lecturers as "lovely" and "nice", and the other did not seem to see this as a professional failing but rather a consequence of lecturers having "marking and meetings". Student participants reported that this norm of independent study was communicated to the students by the lecturing staff. One student reported that lecturers are "always telling the students that this isn't high school", and that the lecturers' "can't run after the students 
if they don't take their studies seriously". One lecturer reminded the class that she finished her studies years ago, and that consequently she does not have to do their work for them. Another student described a lecturer telling the class that they are "very limited" since the students do not want to work independently, but rather rely on him for support.

Since extra-curricular support is considered discretionary, students describe lecturers who help them with reference to their personal character, rather than professional responsibility. For instance, a student, who was in his fifth year of a three-year programme, mentioned throughout our interview how grateful he was to the college for persevering with him even though he is taking longer than he should. He describes the lecturers as extremely knowledgeable and patient; giving of their time, even if one is failing. Two students described supportive lecturers as either "so sweet" or "very sweet", while another participant described a lecturer who had helped her as "very patient".

Consequently, students are very perceptive of the character of the lecturer in question when deliberating whether they should ask for support. One student, for instance, reported "watching... what kind of a person they are". Students broadly distinguished between two kinds of lecturers. The first, of whom they felt comfortable asking questions, were 'sweet' and 'patient'. Humour seems particularly important, as students felt more comfortable with lecturers who joked a lot and engaged with them more informally; or, as one student put it, "to bring people closer to what they are saying". The second kind of lecturer, whom students felt uncomfortable asking questions, were 'moody', quick to anger, and disinterested in students' participation. Students described lecturers who were constantly shouting, and one student described not approaching a lecturer who did not look up from her phone when one asked a question, insisting she could multitask. Another participant reported not approaching a particular lecturer for help after class, as she found him nasty, belittling and hurtful.

In sum, students' understanding of college entails a lack of entitlement for support from the institution, dovetailed by a conception of adulthood as entailing independence.

Consequently, students appear to accept that academic support is limited to classroom instruction as a matter of course, and regard additional support as discretionary and subject to the generosity of the lecturer. For students, not receiving additional support is normalised. Students subsequently refer to judgements about the lecturer's character when 
deliberating as to whether to ask for help; and conversely, lecturers who do not engage with students informally are considered unapproachable. In contrast, as students do not refer to lecturers' professional duties when discussing support, the provision of support seems to be considered a function of personal kindness rather than professional responsibility.

\section{Being responsible for oneself}

These conceptions of college and adulthood as entailing independence leaves students solely responsible if they fail, or fail to seek help, even if it is difficult. All student participants blamed students themselves for failing, regardless of whether they were discussing themselves or their peers. This is underpinned by a belief that "all the information [one] needs to pass is there" and thus "there is no excuse to fail [sic]". Likewise, for another student:

"You know, sometimes I blame myself for failing some subjects, because our lecturers are doing everything for us to pass... I blame myself for failing at some point because the info for me to pass is there. I have a laptop, access to internet at school, teachers, lecturers, a lot of time, we have everything. At some point, when I'm at home, I say, eish [exclamation of resignation], I made a mistake somewhere, somehow."

However, student participants recognised that poverty made it harder for them to succeed. Narrating the challenges facing students in general, they described students having chores to do at home, or being the primary breadwinners in their family, or not having enough money for the taxi fare, as well as the stress created by financial uncertainty more generally. Two students who were studying computer programming described how difficult this was when one did not have a computer or laptop, or in one instance, electricity at home; instead, students were expected to write out the code by hand and then try inputting it into the computers in the Resource Centre when these were available. Another student who came from a rural area described the prejudice he experienced from other students about the undesirability of his home town, as well as the pressure students felt to own consumer items such as advanced phones or fashionable clothes.

Nonetheless, a lack of personal resources did not seem to imply for any of the student participants that students could not pass, or that the college was responsible for addressing 
these challenges. Rather, poverty and financial constraint appeared to be a challenge that students could and were expected to surmount. As I recorded a student ('S') saying in my fieldnotes:

He says it's up to you to cope with this [people looking down on rural areas] though - it's up to you to tell yourself that you're free to study. "The laptop is not going to write the test for you", and, even without a laptop, $\mathrm{S}$ still passes.

Moreover, the perception that all or most of the student body faced similar challenges, as well as the belief that the college was already aware of these difficulties, meant that student participants saw little point in informing the staff about these difficulties.

Furthermore, while student participants recognised that one needed confidence to approach the lecturer, they implicitly absolved the lecturer of any responsibility to be more approachable or put students at ease. For illustrative purposes, when I asked a student why other students did not ask the lecturer for help, he responded: "They are not saying anything because they don't have the guts to stand up and voice their opinions." This locates the problem and the responsibility unequivocally with the students. Similarly, another student argued that the reason some students do not get help is that they do not have enough self-drive, which is what attracts lecturers to help you.

Moreover, student participants reported feeling less entitled to ask for support if they had already been provided with some support, even if that support was ineffective or insufficient. It appears to be relatively common for lecturers to ask the entire class as a collective if they understand. Invariably, this receives a chorus in the affirmative, although it seems that students respond in this way even if they do not understand. However, two student participants factored this response into their deliberations about seeking support. One of these students was concerned that he could not ask a lecturer for help after class if he had said during the class that he had understood. The other described a lecturer expressing surprise at a students' complaint about not understanding, as that student had previously said that they had understood.

In sum, students believe that students who are failing are themselves to blame, even if they recognise that poverty poses significant challenges. This is particularly relevant in light of low through-put rates at the college; failing may create a psychological burden of self-blame 
for students, even if under such circumstances succeeding academically may be unlikely. Moreover, this may explain in part why some students drop out of college without seeking support. Students also feel less able to ask for help if they believe an effort has already been made for them. Consequently, ineffective efforts to help students may do harm in simultaneously under-supporting students and making it difficult for them to seek help themselves.

\section{Not being a burden and not being seen to be stupid}

In light of this conceptualisation of college, adulthood and responsibility, students feared how the act of asking for support would reflect on them as individuals.

The first concern is being perceived as stupid. Two students explicitly stated that they did not ask questions, for fear that people would think they were too slow to understand the work. Another student feared approaching lecturers after class, even privately, because "it would be like [the student] was dumb". This applies even to the lecturers she likes and finds otherwise approachable. This suggests that, even if there is not a negative response from the lecturer, students still fear that their estimation in the eyes of others will decline.

The second concern is being perceived as a 'burden'; someone who is constantly in need of support. Three students, for instance, were concerned about being seen to be the kind of person who is always needing help, is unable to help themselves, and relies on the work of other people without doing the work themselves. One of these students stressed that he wants to be popular and fit in, and that being a 'burden' is antithetical to this. Even being seen to have a problem is a cause for concern. Another described feeling embarrassed about going to the office with a problem, as the other students who were there would also see him. The third student expressed not requiring support as important to his self-identity: "I don't want people to think that I am a burden to them. That's how I am." This impeded this students' ability to ask for help from his peers. He expressly did not want other students to think he was a burden on them, or that he was not doing his work and relied on them instead.

In sum, students' fear of being seen to be stupid or a burden creates an obstacle to seeking support. That a student who asks too many questions is considered stupid or a burden 
however, may be shaped by students' conceptualisations of college and adulthood which foregrounded independence and personal competence.

Consequently, the students in this study considered requiring substantial help to be an embarrassment, and at odds with being a college student and an adult. These students believed that it was their responsibility to overcome any challenges they were individually facing. This is essentially a conceptualisation of college institutions as being responsible for the provision of minimal or no support. Nonetheless, the students reported significant challenges to succeeding academically, which are of the nature envisioned by widening access to further education and training in the SSS Manual.

\section{Discussion}

While SSS Manual frames student support in terms of student deficit, which the institution has the responsibility to accommodate, the students in this study appear to hold a different conception of student support. Although these students still foregrounded student deficit, they nonetheless believed that the responsibility for addressing this deficit lay with the students themselves, to such an extent that to require support from the institution reflected negatively on one's status as a college student and as an adult. Nonetheless, the student body has a whole appeared to face significant and material challenges to succeeding academically.

In short, the SSS Manual assumes the 'totalist' model of support (foregrounding student deficiency, and entailing institutional change to address this), based on what appears to be an accurate assessment of students' needs. However, the students assume the 'thin' model of support (foregrounding student deficiency, while absolving the institution of responsibility), despite lacking the means to fully succeed without support.

The gulf between students' and institutions' perspectives on academic support invites an important reassessment of the apparent consensus on student support internationally. While policy-makers and educational institutions in the United Kingdom, Australia, New Zealand, and South Africa may have accepted that students' responsibility of their academic failure is limited, the students themselves may have been left behind. This is cause for concern, as students' beliefs may have considerable implications for the design and implementation of student support services. Even if support is provided, students may be 
reluctant to use it if doing so conflicts with what they believe the behaviour and responsibilities of an ideal college student are.

\section{The nature of support}

This gulf is also a contribution to the debate on the appropriate nature of support, and in particular, whether it risks undermining the autonomy of students (Myers, 2013). Although the SSS Manual foregrounds students' deficit, the students themselves appear to reject this in favour of a discourse of self-reliance. This compliments Clegg, Bradley, and Smiths' (2006: 108) study of students' discourses of help-seeking in the UK, which found that students were reluctant to ask for help as they perceived their challenges to be their "own" problem.

This corroborates research on youth perspectives in South Africa more generally. Swartz, Harding and De Lannoy (2012: 31), in their analysis of two ethnographic studies of youth aspiration in South Africa, argue that their participants resisted attributing difficulties in their lives to structural disadvantage, with one participant commenting that "references to the past Apartheid were 'becoming an excuse for black people' not achieving". Instead, these youth believe that they will have full access to the opportunities that are present in the 'New South Africa'", and take personal responsibility for their failure to take advantage of this (Swartz et al., 2012: 31, 35).

Furthermore, this study compliments recent research of students' notions of responsibility in the United States. Brion-Meisels' (2014) delineates between a discourse of self-help, independence, and adulthood, and one of childhood and reliance on adults. In the former, students justify not seeking help in terms of having to cope on one's own; constructed this way, seeking help was a sign of weakness which was to be avoided. Conversely, in the latter, students justify accessing support by arguing that young people must seek and require the guidance of adults in order to flourish. Brion-Meisels (2014: 322) argues that both narratives borrow from societal discourses, as she links the former to notions of American individualism, and the latter to a conception of adolescence which constructs youth as vulnerable to deviance without adult guidance. Only a small minority of participants invoked exclusively one discourse however, with the majority drawing on both at different moments (Brion-Meisels, 2014: 327). Brion-Meisels (2014: 327) argues that subsequently some 
students experience cognitive dissonance in feeling that they both require help and feeling "really dumb" if they ask for it.

\section{The risks of pastoral support}

The ethnographic nature of this study, in providing insight into students' experiences, illustrates the potential risks of pastoral forms of student support. These risks may be especially acute when the responsibilities of students, and what they are owed by the institution, are unclear.

For instance, Brion-Meisels (2014: 316) has noted the distinction in the literature between the benefits of perceived and received support. While the former refers to support that an individual believes they are able to access, the latter refers to the number of support services offered by an institution (irrespective of whether individuals believe they can access them). While perceived support has been linked in positive outcomes, both in terms of mental and physical health, the same is not true for received support ( Brion-Meisels, 2014: 316).

In this study, students reported an unwillingness to ask for help if they believed that support had already been provided, even if this support was inadequate, as they did not want to tax the generosity of the staff who were helping at their discretion. This is a challenge to the dichotomy of support needing to be perceived as support to be beneficial. In this study, it is not that students fail to perceive the support available to them. It is the opposite; the support that is received is inadequate, but students nonetheless perceive it as support. In the context of students' assumptions about independent study and not wanting to be a burden, it is this disjunction presents a barrier to students' help-seeking.

Similarly, Yorke and Thomas (2003: 67) argue that how students experience the institutional environment as being 'friendly' is a key factor in student retention. It is particularly important that students feel a sense of 'belonging' or 'relevance' in the institution, as well as belief that "it will assist them realise their goals (whether these are personal, social or instrumental)" (Yorke and Thomas, 2003: 67). Additionally, students' perception of the formality associated with the support has also been reported as a factor in student retention (Raviv, Vago-Gefen, and Fink, 2009: 485), with more formal support services such as psychologists being associated with a greater level of stigma, while informal support 
services such as friends or family bear "a lower psychological cost" and are "likely perceived as less threatening to the self".

The students in this study felt gratitude to their lecturers for being helped, whom they considered generous and supportive. However, because they believed their assistance was discretionary, this limited the extent to which these students asked for support. Thus, it is the substantive quality of the 'friendliness' of the institutional environment that appears key to understanding its influence on students' help-seeking. In this study, students' understanding of the informal 'friendliness' of the staff may have enabled students' to initially request help, but discouraged it after a certain point, within the context on an institution that was essentially unsupportive.

Students' reliance on their perception of a lecturer's character when deciding whether to ask for help, rather than the lecturer's professional duties, raises a challenge for strategies which aim to provide student support. It may be desirable, for instance, to redesign systems of academic support to accommodate these beliefs by focusing specifically on building relationships between the providers and prospective users of support. However, this might not be without risk, as such an effort may reinforce the belief that student support is discretionary, rather than something that students are entitled to. If one believes that support is something that is due to students, and something that all students require, then it is ethically dubious to leave the provision of support dependent on the discretion and character of particular providers.

\section{Limitations and future research}

If there is such a large gulf between how students and institutions conceptualise academic support, one would expect mechanisms of support established in this context to have limited uptake from students or unanticipated harmful consequences. This is especially pertinent in light of the rapidly widening access to higher education, particularly in developing countries like South Africa, as educational institutions grapple with how to support ever increasing numbers of 'non-traditional' students.

Although the ethnographic approach of this study enabled the researchers to explore how students understood and related to academic support, the qualitative nature of this 
methodology nonetheless presents limitations which will need to be addressed through future research.

First, this study did not attempt to make statistically generalisable claims about the student population in South Africa or elsewhere. Further studies will need to access much larger sample sizes, and employ more deliberately representative sampling, in order to make such claims. Second, this study similarly did not attempt to investigate the relationship between students' beliefs about support and their actual patterns of help-seeking. Further studies would either need to employ experimental methodologies, or otherwise collect sufficient data to make persuasive claims about correlation. Nonetheless, the framework of different models of support provided by this paper should prove useful for both of these purposes. One may, for example, administer a simple survey inviting students to rate their agreement with the different axioms of each model.

In addition, the perspectives of lecturers and student support staff have been neglected in this study, despite their importance. This, too, will require further research, and will elucidate whether the challenge is in conveying the policy position from government to educational staff, and/or from educational staff to students.

\section{Conclusion}

The present paper sought to reflect on students' perception of academic support, with particular focus on how students understood the division of responsibility for academic success between themselves and their educational institutions. The paper reported on the findings of a study which sought to consider how academic support within TVET colleges is conceptualised by the South African Department of Higher Education, and by students in TVET colleges, respectively. The study found that the Department of Higher Education endorses a model of academic support which places the burden of responsibility on the educational institution for supporting struggling students, who are understood to constitute a significant proportion of the student body. Conversely, the students regard themselves as exclusively responsible for their academic access and consider academic support from the institution as antithetical to their notion of a 'college student'.

The gulf between how academic support is conceptualised on an institutional level, and how it is conceptualised by the students who are expected to access it, is concerning, and one 
would expect this to hamper the efficacy of the student support services made available. The efficacy of these services may be increased through understanding and meeting students' present beliefs about student support. Alternatively, a different approach to student support, which challenges how students position themselves in relationship to TVET colleges, may be more desirable. This remains to be seen, and further research will be required as these mechanisms of student support are developed.

The impetus to expand access to TVET, and the subsequent difficulties with student throughput, are not unique to South Africa; and neither are the challenges in building effective student support institutions unique to the TVET sector. The concerns raised by this study therefore have relevance internationally and for educational institutions more broadly. Thus far, the agenda has been set by international organisations and national governments. However, unless student perspectives are understood, engaged with, and taken into account, the efficacy of any intervention may be limitedii.

\footnotetext{
'The SSS Manual was released prior to the establishment of the Department for Higher Education and Training.

ii The authors acknowledge the support and reflections of Pam Christie, and Natasha Robinson in writing and thinking about this research, and are indebted to Luzuko Diniso and Olwam Mnqwazi for assistance with their fieldwork. The authors are also grateful for the feedback from two anonymous reviewers. The study reported here was conducted by the first author and formed the basis of a thesis submitted in fulfilment of the requirements for the degree of Masters in Science in Education (Comparative and International Education). The funding received from the Chevening Scholarship, and St. Anne's College of the University of Oxford, is gratefully acknowledged.
} 